\title{
ENTOMOFAUNA EM CAPÍTULOS DE PICÃO-PRETO ${ }^{1}$
}

\author{
RITA C.S.MAIMONI-RODELLA ${ }^{2}$, LUCIA T. C. NEDER ${ }^{3}$, ADRIANA O. FIDALGO ${ }^{3}$ e YURIKO A. N. P. YANAGIZAWA ${ }^{2}$
}

\section{RESUMO}

A ocorrência de insetos fitófagos e de himenópteros parasitóides a eles associados, presentes em capítulos de Bidens pilosa são descritas para as condições do município de Botucatu, SP. Foram encontrados predadores de sementes da ordem Diptera, pertencentes aos gêneros Dioxyna, Melanagromysa e outro não identificado. As moscas Dioxyna depositam seus ovos no interior dos aquênios em estágios iniciais de desenvolvimento, permanecendo no interior do fruto até a emergência do adulto. Melanagromysa localiza-se entre as flores centrais desenvolvendose externamente aos aquênios. Foram observadas oscilações cíclicas e acopladas entre as curvas de abundância dos fitófagos e dos himenópteros parasitóides.

Palavras-chave: Bidens pilosa, predação de aquênios, dípteros, himenópteros.

\section{ABSTRACT \\ Entomofauna in floyer heads of common blackjack}

Phytophagous diptera and parasitoid hymenoptera occurence on flower heads of Bidens pilosa are related at Botucatu, SP, southeastern Brazil. Seed predators were three diptera genera, Dioxyna, Melanagromyza and an unidentified one. The larvae and pupa of Dioxyna

\section{INTRODUÇÃO}

Os diásporos de Bidens pilosa são aquênios desmócoros produzidos em capítulos (De Marinis, 1983) nos quais Needham (1946) registrou visitas de insetos de diversas ordens, os quais utilizam os capítulos de diferentes formas. Dentre eles, os representantes da ordem Diptera se destacam por serem predadores de sementes e pela sua interação com espécies de himenópteros parasitóides. Steyskal (1972) fornece uma lista dos dipteros e himenópteros emergidos de capítulos de B. pilosa var. radiata ocorrente na and Melanagromyza develop inside and between the central achenes, respectively. Coupled ciclic oscillations were observed in phytophagous and parasitoid abundance.

Key word: Bidens pilosa, achene predation, diptera, hymenoptera.

Flórida. Para o Brasil, Lewinsohn (1991) relata a associação entre capítulos de diversas tribos da família Asteraceae e insetos fitófagos das ordens Diptera, Lepidoptera e Coleoptera, com o objetivo de avaliar os padrões de riqueza das espécies envolvidas nessa associação. No entanto, a descrição particularizada da fauna presente em capítulos dos diferentes gêneros citados não é fornecida. Assim, o presente estudo tem por objetivo relatar a ocorrência de dípteros em capítulos de B. pilosa e dos himenópteros parasitóides a eles associados, para as condições do município de Botucatu, SP.

\footnotetext{
${ }^{1}$ Recebido para publicação em 02/03/99 e na forma revisada em 11/04/99.

2 Prof $^{\circ}$ Assistente Doutor, IBB/UNESP, Distrito de Rubião Jr. C.P. 510, CEP: 18618-000, Botucatu/SP.

3 Bióloga e ex -estagiária do Dept ${ }^{\circ}$ de Botânica, IBB/UNESP.
} 


\section{MATERIAL E MÉTODOS}

As observações e a coleta de capítulos de B. pilosa foram realizadas durante os períodos de março a maio de 1983 e de março a setembro de 1993. As unidades atacadas eram reconhecidas no campo por apresentarem alterações marcantes, já que nelas os aquênios maduros permanecem aderidos uns aos outros e circunscritos pelas brácteas involucrais. Em cada coleta, 10 capítulos predados eram recolhidos e mantidos individualmete, em condições de laboratório, em frascos de vidro contendo algodão úmido. Os insetos adultos que emergiam eram retirados dos frascos e conservados em álcool 70\% e, posteriormente, identificados até o nível de família e/ou gênero. Avaliou-se ainda o número de insetos emergidos para a obtenção do número médio de insetos por coleta, durante o período de estudo de 1993. A quantidade e a localização das pupas dos insetos fitófagos foram determinadas através da observação dos capítulos atacados cortados transversalmente.

\section{RESULTADOS E DISCUSSÃO}

Os insetos emergidos a partir dos capítulos coletados estão apresentados na Tabela 1. Moscas do gênero Dioxyna depositam seus ovos no interior dos aquênios em estágios iniciais de frutificação; as larvas que aí se desenvolvem se alimentam das sementes sem destruir o pericarpo havendo, neste processo, liberação de um líquido pegajoso que mantém os aquênios aderidos entre si, não permitindo que o capítulo se abra quando maduro, como normalmente ocorre. Isso constitui uma forma de proteção para o desenvolvimento das pupas até a emergência do inseto adulto. Estas observações são concordantes com os relatos de Needham (1946). As larvas de Melanagromyza ocorreram em capítulos em floração, localizando-se entre as flores centrais, as quais eram danificadas ou consumidas por elas. Neste caso, nos capítulos maduros, as pupas se localizavam externamente aos aquênios sendo, portanto, aparentemente mais expostas que as de Dioxyna.

TABELA 1. Entomofauna presente em capítulos de B. pilosa, município de Botucatu, SP

\begin{tabular}{llll}
\hline Ordem & Família & Gênero & Atividade \\
\hline Diptera & $\bullet$ Tephritidae & $\bullet$ Dioxyna & Predadores de sementes \\
& & $\bullet$ Não identificado & \\
& $\diamond$ Agromyzidae & $\diamond$ Melanagromyza & \\
& & Não identificado & Parasitóides \\
\hline
\end{tabular}

A análise dos capítulos atacados revelou uma certa constância na localização dos aquênios danificados. Verificou-se que aqueles de localização mais central são os preferidos tanto por Dioxyna como por Melanagromyza. No caso de Dioxyna, que é espécie endófaga, diversas moscas podem se desenvolver em um único capítulo, o que pode ser avaliado facilmente pela quantidade de aquênios ocupados pelas pupas íntegras ou já abandonados pelos insetos adultos.
Os aquênios periféricos nunca se encontram atacados sendo possível atribuir a eles uma função de proteção aos aquênios centrais. Isto, associado ao fato do capítulo predado não se distender expondo os diásporos, cria um ambiente fechado que favorece o desenvolvimento das pupas.

$\mathrm{O}$ número médio de dípteros $\mathrm{e}$ himenópteros parasitóides emergidos no período de março a setembro de 1993 encontra-se na 
Figura 1. Os dados mostram a ocorrência de oscilações cíclicas e acopladas entre as curvas de abundância dos fitófagos e dos parasitóides. Interações desta natureza podem gerar ciclos regulares na abundância de ambas as populações interagentes porém, atribuir uma causa específica para estes padrões, bastante freqüentes na natureza, é geralmente difícil, em decorrência dos inúmeros fatores envolvidos, além das interações entre as duas populações em foco (Begon et al., 1996). Apesar disto, os efeitos reguladores decorrentes do ataque dos parasitóides sobre a dinâmica populacional dos herbívoros são bastante conhecidos. No entanto, a sua utilização em programas de controle biológico de pragas, em grande escala, depende de uma série de conhecimentos básicos (Garcia, 1991) devido a natureza complexa desta interação. Assim, o sistema biológico aqui abordado, envolvendo organismos de três diferentes níveis tróficos, é merecedor de uma investigação mais aprofundada, visando conhecer as implicações do impacto dos predadores de sementes sobre a estrutura e a dinâmica da população de $B$. pilosa, bem como dos parasitóides sobre a dinâmica dos hospedeiros.
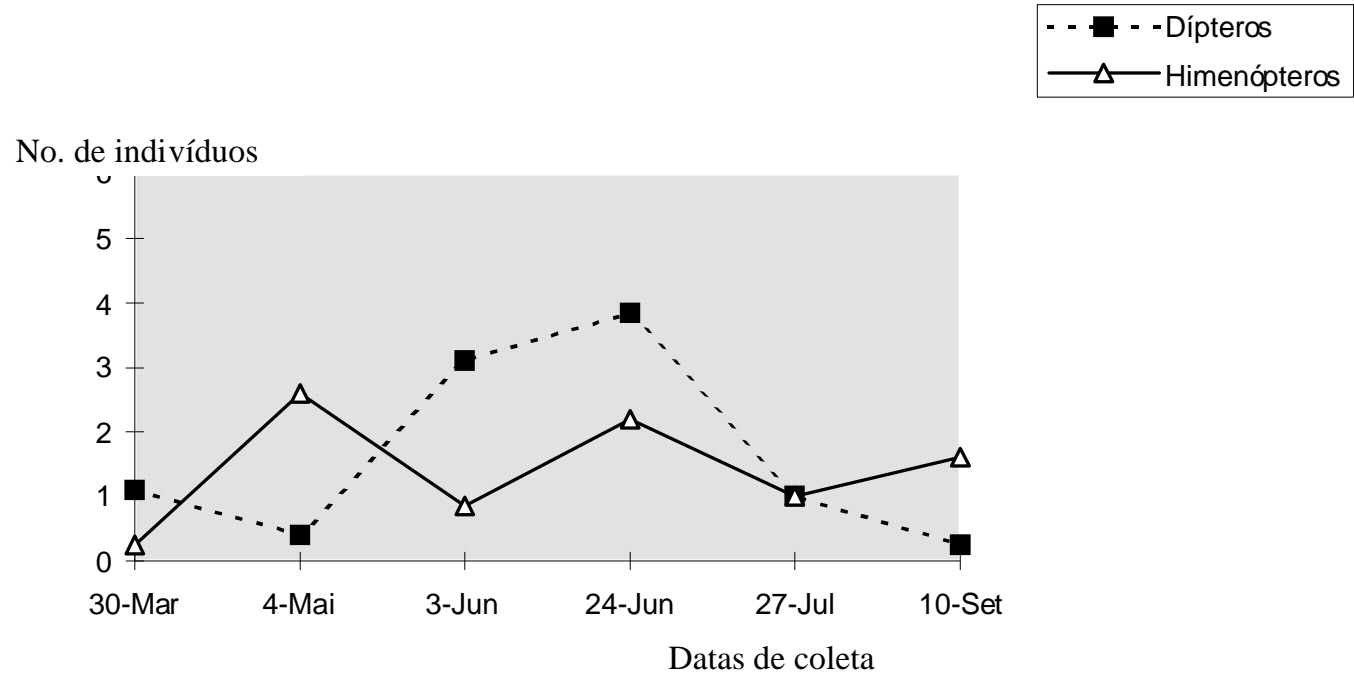

FIGURA 1. Número médio de adultos de espécies de Dípteros e Himenópteros emergidos de capítulos atacados de Bidens pilosa, município de Botucatu, SP, 1993.

\section{LITERATURA CITADA}

BEGON, M., HARPER, J.L., TOWNSEND, C.R.

Ecology: individuals, populations and communities. 3ed. Oxford: Blackwell Science, 1996. p.369-401.

DE MARINIS, G. Organização do capítulo frutífero e heterocarpia em Bidens pilosa $\mathrm{L}$.

Turrialba, v. 33, p. 197-202, 1983.
GARCIA, M. A. Ecologia nutricional de parasitóides e predadores terrestres. In: PANIZZI, A.R., PARRA, J.R.T (Eds). Ecologia nutricional de insetos e suas implicações no manejo de pragas. São Paulo: Manole, 1991. p.289-311.

LEWINSOHN, T. M. Insects in flower heads of Asteraceae in southeast Brazil: a case study on tropical species richness. In: PRICE, P.W. et al. (eds): Plant-animal interactions: evolutionary ecology in 
tropical and temperate regions. New York: John Wiley \& Sons, 1991. p.525-559.

NEEDHAN, J. G. An insect community lives in flower heads. Nat. Geogr., v.90, p.340-356.1946.

STEYSKAL, G. C. The dipterous fauna of the heads of Bidens pilosa. Flo. Ent., v.55, n.2, p.87-88, 1972. 